\title{
ACUTE RESPIRATORY DISTRESS SYNROME (ARDS) CAUSED BY INFLUENZA A/H1N1 INFECTION IN A 10-YEAR-OLD GIRL TREATED WITH ANTIVIRAL THERAPY AND EXTRACORPORAL MEMBRANE OXYGENATION (ECMO)
}

\section{Bosis $S^{1}$, Tagliabue $C^{1}$, Pinzani $R^{1}$, Marchisio $P^{1}$}

1Pediatric Highly Intensive Care Unit, Department of Pathophysiology and Transplantation, Università degli Studi di Milano, Fondazione IRCCS Ca' Granda Ospedale Maggiore Policlinico, Milan, Italy

\section{BACKGROUND}

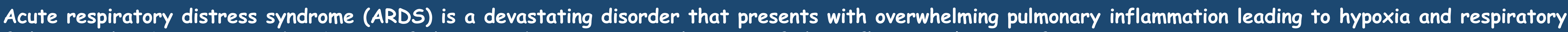
failure. It has been reported to be one of the most devastating complications of the Influenza A/H1N1 infection.

\section{CASE REPORT}

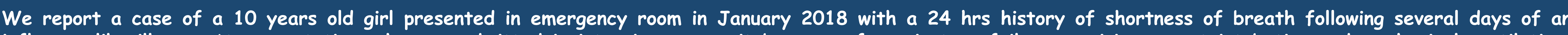

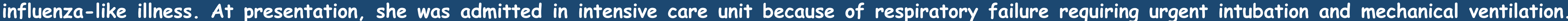

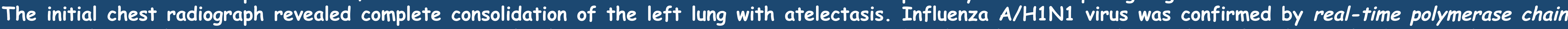

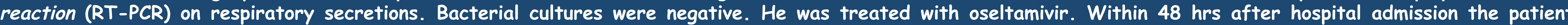

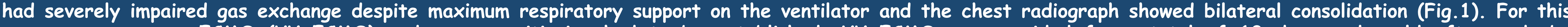

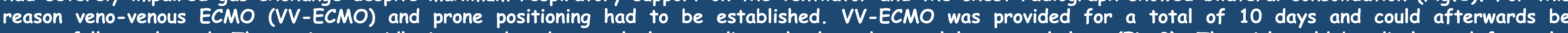

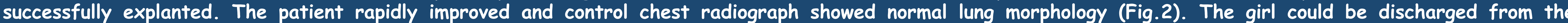
hospital after a total of 22 days with full resolution of symptoms.
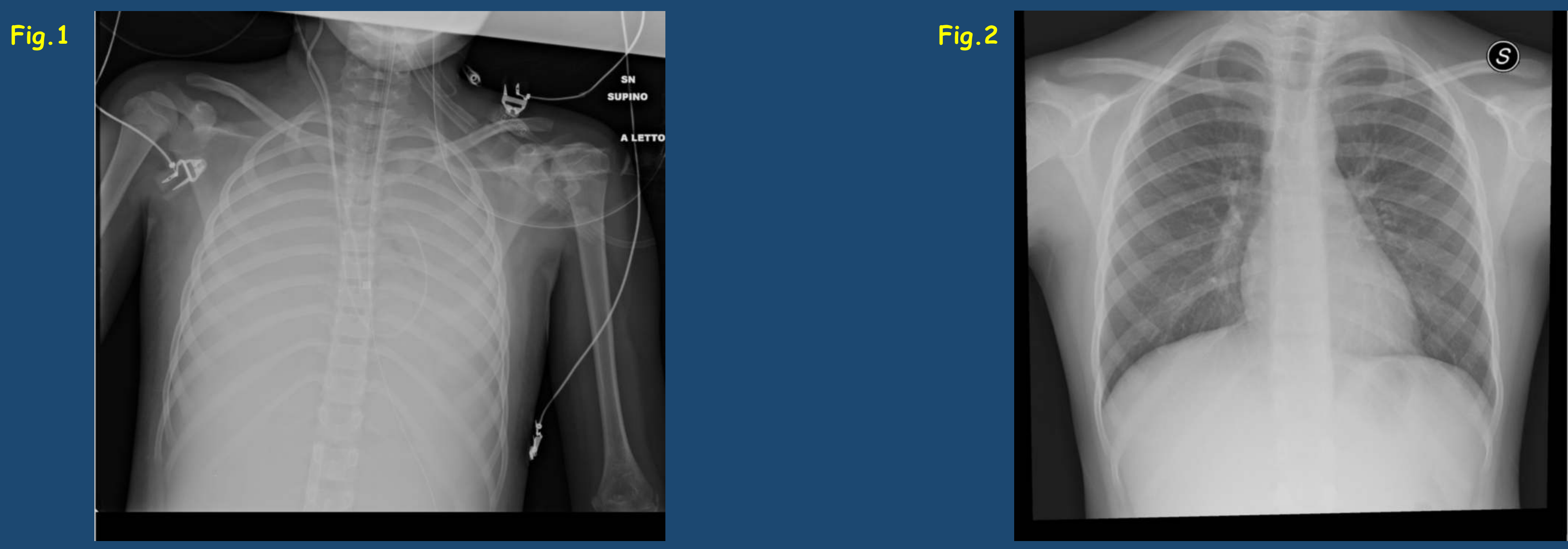

\section{CONCLUSIONS}

These findings suggest that anti-viral drugs and ECMO can play an important role in the improvement of ARDS caused by Influenza A/H1N1. However, influenza vaccination remains the best strategy to prevent complicated influenza. 